\title{
Chronic lymphocytic leukaemias and non- Hodgkin's lymphomas by histological type in farming-animal breeding workers: a population case-control study based on job titles
}

Dino Amadori, Oriana Nanni, Fabio Falcini, Ariele Saragoni, Vittorio Tison, Antonina Callea, Emanuela Scarpi, Miranda Ricci, Nada Riva, Eva Buiatti

Divisione di

Oncologia Medica

(Medical Oncology

Unit), Forlí, Italy

D Amadori

F Falcini

Istituto Oncologico

Romagnolo (Oncology

Institute of Romagna),

Forlí, Italy

O Nanni

A Callea

E Scarpi

M Ricci

N Riva

Servizio di Anatomia

Patologica e

Citodiagnostica

(Department of

Pathology), Forlí,

Italy

A Saragoni

Servizio di Anatomia

Patologica e

Citodiagnostica

(Department of

Pathology), Cesena,

Italy

$\mathrm{V}$ Tison

Unitá di

Epidemiologia,

Centro per lo Studio e

la Prevezione

Oncologica

(Epidemiology Unit,

Center for Study and

Prevention of

Cancer), Firenze,

Italy

E Buiatti

Correspondence to:

Dino Amadori,

Divisione di Oncologia

Medica, Ospedale

Medica, Ospedale

Pièrantoni, Via C Forlan

Accepted 7 March 1995

\begin{abstract}
Objectives-A population based casecontrol study was conducted in a highly agricultural area in the north east of Italy to evaluate the association between farming and animal breeding and the risk of developing non-Hodgkin's lymphoma (NHL) and chronic lymphocytic leukaemia (CLL).

Methods-Occupational histories and other data were collected by personal interview on 164 NHLs, 23 CLLs, diagnosed in 1988-90, and on 977 controls. This paper only reports the results of the analysis relative to the coding of job titles through the modified International Labour Office (ILO) classification. Estimates of odds ratios (ORs) for occupational variables were calculated, after adjustment for sex, age, altitude of municipality, first degree familiarity, and previous Herpes zoster infection.

Results-From the analysis of the most frequent occupational categories, no occupation showed a significantly high risk. When the two job titles farmers only and farmer-breeders who are also involved in animal breeding are classified within the extremely varied occupation of agriculture or animal-breeding or fishing, a high risk for NHLs and CLLs is seen in the farmer-breeders (OR 1.79, 95\% CI 1·22-2.63). Analyses according to histological type show that the risks are concentrated in CLLs and in low grade NHLs. No effect or trend by period at work or duration of employment in farming and animal breeding was found.

Conclusion-Subjects working in agriculture associated with animal breeding are at high risk of NHL/CLLs, particularly CLLs and low grade NHLs. This finding could be related to the use of chemicals in agriculture or to exposure to animal transmitted diseases or specific chemicals used in animal breeding.
\end{abstract}

(Occup Environ Med 1995;52:374-379)

Keywords: agriculture; animal breeding; chronic lymphocytic leukaemia; non-Hodgkin's lymphoma
Since the 1970 s several epidemiological studies have been conducted to evaluate the risk of cancer among farmers. ${ }^{1-21}$ Although the results have not been consistent, many studies have reported substantial increases in soft tissue sarcomas and lymphomas, ${ }^{13-21}$ which are attributable mainly to exposure to phenoxyacid.

In Italy, incidence of non-Hodgkin's lymphomas (NHLs) based on the ninth revision of the international classification of diseases (ICD-9, 200 and 202) for the period 1983-7 ranges from $7 \cdot 0$ to $16 \cdot 2 / 100000 /$ year for males and from $4 \cdot 3$ to $13 \cdot 7 / 100000 /$ year for females (standard population of Italy, 1981). The incidence of all leukaemias (ICD-9, 204 to 208 ) varies from 8.6 to 13.4 in males and from $5 \cdot 7$ to $9 \cdot 4$ in females.

In the province of Forli there is a high level of employment in agriculture and animal breeding and a widespread use of chemicals, with farm workers currently comprising about $20 \%$ of all working residents in the area.

With reference to the same population, the tumour registry of Romagna reports the second highest incidence in males $(15.2 /$ 100 000/year for NHL and 13.2/100 000/year for leukaemia) and the highest Italian incidence for both groups of tumours in females. ${ }^{22}$

In the years 1988-90 a population based case-control study was conducted in a subarea of the province of Forli that comprised 28 small municipalities (local health unitsLHU-38 and 39, with a resident population of about 342000 at the 1981 census) to evaluate the association between farming or animal breeding and haemolymphopoietic malignant tumours and soft tissue sarcomas. This paper presents the first results of the case-control study limited to farming and animal breeding, NHL and chronic lymphocytic leukaemia (CLL) in Forlí .

\section{Materials and methods}

Between January 1987 and December 1990 we consulted the population tumour registry of Romagna to identify all incident cases of NHL and CLL, aged 15-75 years, among residents of the subarea of the Forli province who had been diagnosed haematologically $(n=4)$ or histologically $(n=188)$, excluding 
known HIV positive subjects. Cases of NHL were further classified by histological type with a modified Kiel classification. ${ }^{23}$ All histological specimens were reviewed by one pathologist (AS). Cases of NHL and CLL were first considered in the analysis together, as a frequent pathological and clinical misclassification between NHL and CLL has been described because of substantial biological similarities between the two diseases. ${ }^{24}$ Further analysis was conducted separately for the main histological types.

Among 192 cases thus identified, five refused to cooperate $(2 \cdot 5 \%)$ and 18 died before the interview. The next of kin or general practitioner were interviewed for the deceased patients as well as for six others in an extremely poor state of health (total $=24$ $(12 \%)$, seven husbands, nine sons or daughters, four parents, three brothers, and one general practitioner). The present analysis is therefore based on a total of 187 cases. The control group consisted of a random sample of subjects residing in the study area identified through a residents' list and frequency matched to the cases according to sex and five-year age groups. In the study on haemolymphopoietic tumours and soft tissue sarcomas, 977 population controls were contacted. One hundred and eighteen $(12 \%)$ subjects refused to be interviewed, mainly because of a lack of interest and were thus substituted by the next subject on the residents' list. All 977 controls were considered in the present analysis. This represents about five controls for each case. Table 1 presents the distribution of cases and controls according to sex, age, and histological diagnosis. Two cases of mycosis fungoides were included when all cases were analysed together but excluded when the analysis by histological type was performed.

Cases and controls were interviewed with an occupational questionnaire entitled "agriculture and health", which asked for information on residential history, community life, dietary habits, smoking, alcohol consumption, family history of cancer, medical history, use of drugs, exposure to radiation, and work history. Exposures in childhood were evaluated by asking if the subject used to help the family in agriculture and in animal breeding before the age of 13 .

The work history section was structured in

Table 1 Case-control study on NHL and CLL in agriculture: distribution of cases and controls by age, sex, and histological type of malignancy

\begin{tabular}{ccccc}
\hline & $\begin{array}{l}\text { Cases } \\
n(\%)\end{array}$ & $\begin{array}{l}\text { NHL* } \\
n(\%)\end{array}$ & $\begin{array}{l}\text { CLL } \\
n(\%)\end{array}$ & $\begin{array}{l}\text { Controls } \\
n(\%)\end{array}$ \\
\hline Sex: & & & & \\
$\quad$ Male & $106(56 \cdot 7)$ & $92(56 \cdot 1)$ & $14(60 \cdot 9)$ & $548(56 \cdot 1)$ \\
Female & $81(43 \cdot 3)$ & $72(43 \cdot 9)$ & $9(39 \cdot 1)$ & $429(43 \cdot 9)$ \\
Age (y): & & & & \\
$15-24$ & $3(1 \cdot 6)$ & $3(1 \cdot 8)$ & 0 & $28(2 \cdot 8)$ \\
$25-34$ & $14(7 \cdot 5)$ & $14(8 \cdot 5)$ & 0 & $70(7 \cdot 2)$ \\
$35-44$ & $11(5 \cdot 9)$ & $11(6 \cdot 7)$ & 0 & $59(6 \cdot 0)$ \\
$45-54$ & $30(16 \cdot 0)$ & $24(14 \cdot 6)$ & $6(26 \cdot 1)$ & $150(15 \cdot 4)$ \\
$55-64$ & $48(25 \cdot 7)$ & $42(25 \cdot 6)$ & $6(26 \cdot 1)$ & $235(24 \cdot 1)$ \\
$65-75$ & $81(43 \cdot 3)$ & $70(42 \cdot 7)$ & $11(47 \cdot 8)$ & $435(44 \cdot 5)$ \\
\hline
\end{tabular}

${ }^{\star}$ Histological types, low grade 56 , medium grade 34 , high grade 72 , mycosis fungoides 2. two parts. The first part collected information on the subject's entire work experience and relative time periods. Only occupations lasting one year or more were recorded.

Jobs were initially classified under one of the 21 working categories listed in the questionnaire and then further classified according to 254 listed jobs (modified International Labour Office (ILO) questionnaire). Subjects who reported having been employed in agriculture or animal breeding for at least one year also completed the second section of the questionnaire in which they were asked to provide detailed information on each of the 10 most widely cultivated crops on each farm of employment as well as on types of animals bred. Details on the occupational questionnaire used can be found in a previously published paper. ${ }^{25}$ Interviews with cases and controls were carried out by three interviewers who had attended periodic training courses.

Fifty seven per cent of cases were interviewed in hospital and $83 \%$ of controls were interviewed at home. About half the subjects interviewed had worked in agriculture at some time in their lives. This paper only reports the results of the analysis relative to the coding of jobs through the modified ILO classification. The variables used in the analysis were as follows: Marital status: married $v$ unmarried. Education: classes defined according to total number of years at school. Migration from south: yes $v$ no. Cigarette smoking: non-, ex-, and current cigarette smokers in low and high categories (cigarettes/day, $\leqslant 20 \quad v \quad>20$ ). Alcohol intake: non-drinkers, current drinkers of $<30,30-60,>60 \mathrm{~g} /$ day. ${ }^{26}$ Altitude of municipality of residence: the municipality of residence was classified according to coding by the Central Institute of Statistics. ${ }^{27}$ Family history of cancer, including tumours of the haemolymphopoietic system: classified as positive if the subject reported one or more first degree relatives affected. Previous Herpes zoster infection: subjects were considered exposed if they reported having had this infection at least two years before the date of diagnosis (cases) or interview (controls).

The association between work in agriculture or animal breeding and risk of NHL or CLL was measured by the maximum likelihood estimate of the odds ratio (OR) as an estimate of risk ratio (RR). First of all a series of univariate analyses on non-occupational variables was conducted. Occupational variables were then analysed, adjusted first by sex and age, then by sex, age, altitude of municipality, first degree familial haemolymphopoietic cancer, and previous Herpes zoster infection. The last three variables were identified through univariate analysis. Unconditional logistic regression analysis was used with case-control status or main histological types of cases as the response variable. ${ }^{28}$ The analysis was carried out with SAS. ${ }^{29} 30$

\section{Results}

Cases of NHL or CLL and controls were similar for sociodemographic and lifestyle 
characteristics such as marital status, education, migration from the south, alcohol intake, and cigarette smoking. In the univariate analysis, three variables were found to be significantly associated with the cases, or to modify the estimates of the multivariate model. These were altitude of municipality of residence, family history of haemolymphopoietic cancer, and previous Herpes zoster infection. A linear logistic regression model was constructed incorporating sex and age. In the model, each of these three variables was adjusted for the others.

Table 2 shows the OR estimates. The OR for subjects resident in hilly or mountainous areas $v$ those living in the lowlands was 0.55 (95\% confidence interval (95\% CI) 0.35 $0 \cdot 86)$. This result may reflect a different distribution of jobs, and within the farming category a different distribution of crops or animal breeding.

Although a positive history of haemolymphopoietic cancer in first degree relatives was not significantly related to the risk, the OR estimate was high (OR 1.92, 95\% CI $0 \cdot 87-4 \cdot 25$ ). Family history of cancer in general or of other types of tumours did not, on the other hand, present ORs greater than one. A positive medical history of Herpes zoster infection was more often reported by cases than by controls (OR 2.09, 95\% CI 1.34-3.27). If the subjects with Herpes zoster are subdivided on the basis of the time from diagnosis of neoplasia (cases) or from the interview (controls) ( $\leqslant 10 \mathrm{y}$ or $>10 \mathrm{y}$ ), the ORs for these two categories, adjusted for the other variables, remain significant (OR 2.34 (95\% CI $1.20-4.57)$ and OR 1.95 (95\% CI $1 \cdot 11-3 \cdot 41)$ respectively). Other diseases that involve the immune system such as asthma, allergic conditions, or eczema were not associated with risk of NHL or CLL.

The same variables were analysed for CLLs and high, medium, and low grade NHLs separately as cases $v$ all controls. Results were substantially confirmed for each histological type without relevant differences, although some risks lost significance because of small numbers. Table 3 provides OR estimates adjusted by age, sex, altitude of municipality, first degree familial haemolymphopoietic cancers, and previous Herpes zoster infection, for each working category that involved at least 20
Table 3 Odds ratios for NHLs and CLLs according to working categories *

\begin{tabular}{lrrl}
\hline Working category & Cases & Controls & OR $(95 \%$ CI $\dagger$ \\
\hline Medical or health & 4 & 21 & $1 \cdot 12(0 \cdot 37-3 \cdot 33)$ \\
Administrative & 28 & 146 & $0 \cdot 95(0 \cdot 61-1 \cdot 49)$ \\
Business & 90 & 454 & $1 \cdot 07(0 \cdot 74-1 \cdot 54)$ \\
Transportation & 16 & 56 & $1 \cdot 70(0 \cdot 93-3 \cdot 11)$ \\
Agriculture or animal- & & & \\
breeding or fishing & 92 & 442 & $1 \cdot 30(0 \cdot 93-1 \cdot 81)$ \\
Foods & 16 & 73 & $1 \cdot 11(0 \cdot 62-1 \cdot 97)$ \\
Pottery & 3 & 32 & $0 \cdot 48(0 \cdot 14-1 \cdot 61)$ \\
Construction & 29 & 130 & $1 \cdot 27(0 \cdot 79-2 \cdot 05)$ \\
Electrical & 5 & 26 & $1.02(0 \cdot 38-2 \cdot 73)$ \\
Wood & 10 & 50 & $0 \cdot 99(0 \cdot 49-2 \cdot 00)$ \\
Metal & 24 & 109 & $1 \cdot 14(0 \cdot 69-1 \cdot 88)$ \\
Mines & 9 & 20 & $0 \cdot 87(0 \cdot 25-3 \cdot 05)$ \\
Textiles & 10 & 20 & $2 \cdot 29(1 \cdot 01-5 \cdot 18)$ \\
Clothing & 15 & 107 & $0.66(0 \cdot 36-1 \cdot 19)$ \\
Shoes or leather & 4 & 39 & $0.51(0 \cdot 18-1 \cdot 46)$ \\
Others & 45 & 222 & $1.08(0 \cdot 74-1 \cdot 57)$
\end{tabular}

^Only categories with more than 20 subjects were included; subjects may be counted more than once; †Adjusted for altitude of municipality, first degree familial haemolymphopoietic cancer, previous Herpes zoster infection, age, and sex.

subjects. In this, as in the following analyses, the adjustment tended systematically to reinforce the significant associations.

No further significant association was identified through adjustment.

The working categories were not mutually exclusive, and subjects could be counted more than once. The mean (SEM) number of categories in which cases and controls were involved was estimated as $2 \cdot 14(0.07)$ for cases and 2.05 (0.03) for controls.

Analysis of the 21 working categories (with a work experience of at least one year) showed some ORs $>1$. None of these were significant with the exception of the textile manufacturing category, which, before being adjusted for other occupational variables, showed a significant OR of $2 \cdot 29(95 \%$ CI $1 \cdot 01-5 \cdot 18)$. Out of the 254 job titles, those with more than 20 subjects were analysed but no significant results were found. When feasible, the working categories were also analysed for each histological type. Results did not change except for the categories agriculture or animal breeding or fishing in which a high but non-significant risk was limited to CLLs (OR 2.31, 95\% CI $0.92-5 \cdot 78$ ) and low grade malignancy NHLs (OR $1 \cdot 72,95 \%$ CI 0.96-3.06, table 4 ).

The textiles category was also analysed in the same models because a significant OR was initially found. Adjusted for work in
Table 2 Odds ratios for NHLs and CLLs according to altitude of municipality, first degree familial haemolymphopoietic cancer, and previous Herpes zoster infection, adjusted by sex, age, and each variable by the others

\begin{tabular}{|c|c|c|c|}
\hline & Cases & Controls & OR $(95 \% C I)$ \\
\hline $\begin{array}{l}\text { Altitude: } \\
\text { Lowlands } \\
\text { Hill or mountain }\end{array}$ & $\begin{array}{r}163 \\
24\end{array}$ & $\begin{array}{l}770 \\
207\end{array}$ & $\begin{array}{l}1.00 \\
0.55(0.35-0.86)\end{array}$ \\
\hline $\begin{array}{l}\text { First degree familiar } \\
\text { No } \\
\text { Yes }\end{array}$ & $\begin{array}{c}\text { or haem } \\
178 \\
9\end{array}$ & $\begin{array}{l}\text { mphopoic } \\
953 \\
24\end{array}$ & $\begin{array}{l}\text { etic cancer: } \\
1.00 \\
1.92(0 \cdot 87-4 \cdot 25)\end{array}$ \\
\hline $\begin{array}{l}\text { Herpes zoster: } \\
\text { No } \\
\text { Yes }\end{array}$ & $\begin{array}{r}155 \\
32\end{array}$ & $\begin{array}{r}890 \\
87\end{array}$ & $\begin{array}{l}1 \cdot 00 \\
2 \cdot 09(1 \cdot 34-3 \cdot 27)\end{array}$ \\
\hline
\end{tabular}

Table 4 Odds ratios for CLLs and NHLs by histological type in the agriculture or animal-breeding or fishing categories compared with subjects never employed in this working category

\begin{tabular}{|c|c|c|c|}
\hline & \multicolumn{3}{|c|}{ Agriculture or animal-breeding or fishing } \\
\hline & \multirow{2}{*}{$\frac{\text { Never }}{n}$} & \multicolumn{2}{|l|}{ Ever } \\
\hline & & $n$ & $O R^{*}(95 \% C I)$ \\
\hline $\begin{array}{l}\text { Controls } \\
\text { CLL } \\
\text { Low grade NHL } \\
\text { Medium grade NHL } \\
\text { High grade NHL }\end{array}$ & $\begin{array}{r}535 \\
8 \\
23 \\
21 \\
41\end{array}$ & $\begin{array}{r}442 \\
15 \\
33 \\
13 \\
31\end{array}$ & $\begin{array}{l}2.31(0.92-5.78) \\
1.72(0.96-3.06) \\
0.91(0.43-1.92) \\
1.03(0.61-1.72)\end{array}$ \\
\hline
\end{tabular}


agriculture or animal-breeding or fishing, the risk for employment in the textile industry lost significance because several subjects employed in this working category were also employed in agriculture.

Cases and controls were then divided into three main occupational categories: farmers who were only involved in agricultural activities (farmers), those who were also involved in animal breeding (farmer-breeders) and those involved in all other occupations (other workers). As the group of animal breeders not involved in farming activities included only four subjects, these were classified in the farmer-breeders group. The subjects in this group, although also involved in farming activities, thus represented the category of breeders in this population.

Table 5 shows the results for all cases by histological type adjusted for the usual models. When all cases together are considered, the category of farmer-breeders presented an OR of 1.79 (95\% CI 1.22-2.63), whereas farmers had a non-significant risk of 0.89 (95\% CI 0.57-1 40). Analysis by histological type showed that significantly high ORs for farmer-breeders were concentrated in CLLs (OR 3.05, 95\% CI 1.12-8.32) and low grade NHLs (OR $2 \cdot 22,95 \%$ CI $1 \cdot 16-4 \cdot 26$ ). When the farmer-breeders were divided into two groups on the basis of the median duration of work (23 years), no association between NHL or CLL and duration of period of exposure was found, as the two ORs, both significant, did not differ much from each other (OR for $<23 \mathrm{y}, 1.89$, 95\% CI 1.18-3.00; OR for $\geqslant 23$ y $1 \cdot 68,95 \%$ CI $1 \cdot 01-2 \cdot 77)$. Similar results were obtained with tertiles of duration of work.

When the variable exposure in childhood to farming-breeding was evaluated, $41.7 \%$ of cases and $28.3 \%$ of controls reported to have been a farmer-breeder in childhood (OR 2.08, 95\% CI 1.45-2.98). Similar analyses for duration of work in farmers did not give any significant results. The analysis for main job (the work in which each subject was involved for the greatest number of years) in the farmerbreeder category compared with all other workers showed a non-significant OR of $1 \cdot 29$ (95\% CI 0.84-1.99).

In the subsequent analysis farmer-breeders were subdivided according to three categories of working time period. The calendar year 1955 was chosen as cut off time (the year of mass introduction of pesticides and the begin-

Table 5 Odds ratios for NHLs/CLLs and for separate histological types according to occupation in farming and in farming or animal-breeding compared with other workers

\begin{tabular}{|c|c|c|c|c|c|}
\hline & \multirow{2}{*}{$\begin{array}{l}\text { Other } \\
\text { workers* } \\
n\end{array}$} & \multicolumn{2}{|c|}{ Farmers } & \multicolumn{2}{|c|}{ Farmer-breeders } \\
\hline & & $n$ & OR $(95 \% C I)$ & $n$ & OR $(95 \% C I) \dagger$ \\
\hline $\begin{array}{l}\text { Controls } \\
\text { Cases } \\
\text { CLL } \\
\text { Low grade NHL } \\
\text { Medium grade NHL } \\
\text { High grade NHL }\end{array}$ & $\begin{array}{r}541 \\
95 \\
8 \\
23 \\
21 \\
41\end{array}$ & $\begin{array}{r}219 \\
31 \\
5 \\
12 \\
2 \\
12\end{array}$ & $\begin{array}{l}0.89(0.57-1.40) \\
1.62(0.50-5.21) \\
1.30(0.62-2.71) \\
0.27(0.06-1.19) \\
0.82(0.41-1.60)\end{array}$ & $\begin{array}{r}217 \\
61 \\
10 \\
21 \\
11 \\
19\end{array}$ & $\begin{array}{l}1.79(1.22-2.63) \\
3.05(1.12-8.32) \\
2.22(1.16-4.26) \\
1.69(0.68-3.38) \\
1.32(0.72-2.42)\end{array}$ \\
\hline
\end{tabular}

^Including fishermen; fadjusted for altitude of municipality, first degree familial haematopoietic cancer, previous Herpes zoster infection, age, and sex. ning of a period of technological transformation in crop cultivation). The categories by period of employment were classified as follows: start and finish before 1955; start before 1955; finish after 1955; start and finish after 1955. Farmer-breeders who started and finished their work experience before 1955 experienced an OR of 3.41 (95\% CI 1.73-6.70). Those who worked before and after 1955 had an OR of 1.72 (95\% CI 1.07-2.76), and those whose work experience began after 1955 had an OR of $1 \cdot 19$ (95\% CI $0 \cdot 61-2 \cdot 33)$. To allow for an induction latency period, we performed a further analysis with cases and controls excluded if they began work in farmingbreeding less than 20 years before the date of incidence or interview. Cases excluded were seven $(3.4 \%)$, controls excluded were 23 $(2.3 \%)$, and the estimate OR was $0.82(95 \%$ CI $0 \cdot 31-2 \cdot 16$ ).

Finally, the two categories of farmers and farmer-breeders were compared for some variables of their position at work. Farmerbreeders, on average, cultivate a wider variety of crops and farm larger areas of land than farmers; farmer-breeders raise cattle to sell, whereas farmers are only in contact with the livestock they keep for their own personal use. The median duration of employment is much longer among farmer-breeders (23 y) than farmers (14 y). About $50 \%$ of farmer-breeders personally use chemical compounds $v 23 \%$ of farmers; farmer-breeders are more often land owners $(64 \% v 44 \%)$, whereas farmers tend to be employed as farm labourers.

\section{Discussion}

We conducted this population based casecontrol study in the highly agricultural province of Forlí to study the risk factors for NHL or CLLs linked to farming and animal breeding. Some significant results emerged from the sociodemographic variables lifestyle and medical history. The altitude of the municipality of residence, which is a risk factor for these neoplasias, may reflect some differences in the distribution of crops and working procedures in agriculture and animal breeding. In fact, farming in the lowlands as opposed to the hills or mountains generally involves the cultivation of different crops and a heavier use of chemicals.

First degree familial haemolymphopoietic tumours tend to represent a risk factor for the disease. Although previously reported as significant in the medical literature ${ }^{1317}$ it was not so in this case. This variable may be subject to a recall bias between cases and controls. In this study, however, familial tumours in general and other tumours are not associated with risk of NHL or CLLs. From a comprehensive series of questions on diseases linked to the immune system, no disease was found to be associated with the neoplasias with the exception of Herpes zoster infection. This finding is consistent with results from two other studies. ${ }^{1031}$

In our study Herpes zoster infection in cases does not seem to be secondary to the neoplasia 
because subjects were not considered among those affected if they had contracted the infection during a period of up to two years before diagnosis (cases) or interview (controls). As no other diseases investigated show an excess risk, recall bias does not seem to explain this finding either. The high frequency of Herpes zoster infection among cases suggests two main possible explanations: this slow acting virus may interfere as a stimulating factor, accelerating the development of the neoplasia, or, a pre-existing imbalance in the immune system may promote the infection, and in the meantime may be associated with the occurrence of NHL or CLLs.

From the analysis of the most frequent occupational categories, no occupation seems to have a significantly high risk with the exception of textile manufacturing which, however, loses significance when adjusted for other occupational variables in the final model.

When the two large categories of arable farmers and farmer-breeders (who are also involved in animal breeding) were classified within the extremely varied group of agriculture or animal-breeding or fishing, a high risk for NHLs and CLLs was found in the farmer-breeders. The distinction between these two working categories has rarely been considered in previous papers, although animal breeding is expected to be often associated with farming at least in some populations. Several population surveys and other case-control studies on NHL and on CLL have reported significantly higher ORs among farmers in general, with results based on mortality records or incident cases. ${ }^{12} 1732.34$

By contrast, some population surveys have found no increased risks for farmers ${ }^{2579}$ and some case-control studies have reported risks close to one, or at any rate not significant. ${ }^{3468}$ The inconsistency of published data may, to some extent, be the result of a different distribution of these two categories within the broad farmer group. Two hypotheses can be put forward to explain the higher risk in farmer-breeders than in farmers. The first is that breeding cattle is indicative of a more specific and more intensive farming activity. This is confirmed by the fact that farmerbreeders, on average, cultivate a wider variety of crops, farm larger areas of land, and personally use chemical compounds more often than farmers. In this case, the farmer-breeders would appropriately represent a highly exposed category of farmers.

A second hypothesis is that breeding livestock exposes the farmer to specific chemicals used in breeding activities or to the action of biological agents linked to animal diseases (parasites, viruses, etc). Few studies reported excess risk of haemolymphopoietic tumours among farmer-breeders. ${ }^{61322}$ Moreover, the hypothesis of an aetiological role of oncogenic animal viruses in human cancer is suggested in some studies focused on workers exposed to possible viral transmission-for example, abattoir and meat industry workers. ${ }^{35-37}$

The most important histological result shows that the risk for farmer-breeders is consistently limited to CLLs and low grade NHLs. This finding is in agreement with the hypothesis that a certain biological homogeneity exists between these two neoplasias. ${ }^{24}$

We found no trend between duration of employment and risk of NHL or CLL. A high proportion of subjects in the short duration of employment category were actually exposed for quite a long time. Indeed, there were very few subjects exposed for a short period. It is, therefore, impossible to evaluate short duration of employment in this population. Moreover, any effect of duration could be masked by a time period effect linked to the use of chemicals. Exposure in childhood was significantly associated with risk of NHL or CLL. This could be due both to a strong correlation between exposure in childhood and work in farming or animal breeding during adult life and to an early effect of exposure on the risk of the diseases.

Analysis by time period, however, does not give easily interpretable results, as two historical periods of risk emerge, the higher one occurring before the mass introduction of pesticides (around 1955). For farmer-breeders who only worked after 1955, the risk became non-significant. The exclusion of subjects with a latency period of less than 20 years does not contribute to the understanding of this finding. This result could also partially be explained by the fact that in this category a high percentage of the cases began working after the period 1970-5, by which time many farmers were well aware of the toxicological problems linked to their work. The effect of time period could thus be more related to the way of use of chemicals than to their amount.

Other authors have found that the decrease in risk for workers who began to be exposed relatively recently,,$^{3121317}$ may also be explained by the need for a longer period of latency than the usual 15 to 20 years reported in the medical literature. ${ }^{36}$ Unfortunately, in this study the few cases do not allow for evaluation of other hypotheses of latency period.

In conclusion, as far as the relation between farming and animal breeding and the occurrences of NHL/CLL is concerned, the relative risks estimated in our study are significant but not very high. This could be due to the definitions of the histological categories of our exposed subjects, which are broad and generic.

The results from this preliminary analysis point to the possible role of chemicals and of their use in the risk of NHL or CLL. This is limited to some sectors of agricultural or breeding occupations and refers to a specific time period. There is also a possible role for diseases transmitted by animals.

We thank Ms B Branzanti, Ms MG Minelli, and Ms A Giuseppone for the interviews they carried out; and Ms Grainne Tierney for her critical assistance in the preparation of the text. This study was made possible by funding from the the text. This study was made possible by funding from the Romagna (Emilia-Romagna Region), the Lega Italiana per la Lotta contro i Tumori (the Italian League Against Cancer) in Lotta contro i Tumori (the Italian League Against Cancer) in Milan, the Associazione Italiana per la Ricerca sul Cancro (Italian Association for Cancer Research) in Milan, and the Ministero del Lavoro-Direzione Generale della Previdenza e Assistenza Sociale (Ministry of Employment Health and Social Services) in Rome. 
1 Blair A, Linos A, Stewart PA, Burmeister LF, Gibson R Everett G, et al. Comments on occupational and environmental factors in the origin of non-Hodgkin's environmental factors in the origin of
lymphoma. Cancer Res 1992;52:5501 s-2s.

2 Corrao G, Calleri M, Carle F, Russo R, Besia S, Piccioni P. Cancer risk in a cohort of licensed pesticide users. Scand f Work Environ Health 1989;15:203-9.

3 Hoar Zahm S, Weisenburger DD, Babbitt PA, Saal RC Vaught JB, Cantor KP, et al. A case-control study of non-Hodgkin's lymphoma and the herbicide 2,4dichlorophenoxyacetic acid (2,4-D) in Eastern Nebraska. Epidemiology 1990;1:349-56.

4 Franceschi S, Barbone F, Bidoli E, Guarneri S, Serraino $\mathrm{D}$, Talamini $\mathrm{R}$, et al. Cancer risk in farmers: results from a multi-site case-control study in north-eastern Italy. Int $\mathcal{F}$ Cancer 1993;53:740-5.

5 Wiklund K, Dich J, Holm LE, Eklund G. Risk of cancer in pesticide applicators in Swedish agriculture. $\mathrm{Br} \mathcal{F}$ Ind Med 1989;46:809-14.

6 Flodin U, Fredriksson M, Persson B, Axelson O. Chroni lymphatic leukaemia and engine exhausts, fresh wood, and DDT: a case-referent study. $\mathrm{Br} \mathcal{F}$ Ind $\mathrm{Med} 1988$ 45:33-8.

7 Wiklund K, Dich J, Holm LE. Risk of malignant lymphoma in Swedish pesticide appliers. Br $\mathcal{F}$ Cancer 1987; 56:505-8.

8 Pearce NE, Sheppard RA, Smith AH, Teague CA. NonHodgkin's lymphoma and farming: an expanded casecontrol study. Int $\mathcal{f}$ Cancer 1987;39:155-61.

9 Wigle DT, Semenciw RM, Wilkins K, Riedel D, Ritter L Morrison HI, et al. Mortality study of Canadian male farm operators: non-Hodgkin's lymphoma mortality and agricultural practices in Saskatchewan. F Natl Cancer Inst 1990;82:575-82.

10 Franceschi S, Serraino D, Bidoli E, Talamini R, Tirelli U, Carbone A, et al. The epidemiology of non-Hodgkin's lymphoma in the north-east of Italy: a hospital-based case-control study. Leuk Res 1989;13:465-72.

11 Vineis P, D'Amore F, and the Working Group on the Epidemiology of Hematolymphopoietic Malignancies in Italy. The role of occupational exposure and immunodeficiency in B-cell malignancies. Epidemiology 1992;3: ficiency

12 Woods JS, Polissar L, Severson RK, Heuser LS, Kulande BG. Soft tissue sarcoma and non-Hodgkin's lymphoma in relation to phenoxyherbicide and chlorinated phenol exposure in western Washington. $\mathcal{F}$ Natl Cancer Inst 1987;78:899-909.

13 Brown LM, Blair A, Gibson R, Everett GD, Cantor KP, Schuman LM, et al. Pesticide exposures and other agricultural risk factors for leukemia among men in Iowa and Minnesota. Cancer Res 1990;50:6585-91.

14 Brownson RC, Reif JS, Chang JC, Davis JR. Cancer risks among Missouri farmers. Cancer 1989;64:2381-6.

15 Scherr PA, Hutchison GB, Neiman RS. Non-Hodgkin's lymphoma and occupational exposure. Cancer Res 1992, $52: 5503 \mathrm{~s}-9 \mathrm{~s}$

16 Hardell L, Eriksson M, Lenner P, Lundgren E. Malignan lymphoma and exposure to chemicals, especially organic solvents, chlorophenols, and phenoxy acids: a casecontrol study. $B r \mathcal{F}$ Cancer 1981;43:169-76.

17 Cantor KP, Blair A, Everett G, Gibson R, Burmeister LF Brown LM, et al. Pesticides and other agricultural risk factors for non-Hodgkin's lymphoma among men in Iowa and Minnesota. Cancer Res 1992;52:2447-55.
18 Blair A, Hoar Zahm S. Patterns of pesticide use among farmers: implications for epidemiologic research. Epidemiology 1993;4:55-62.

19 International Agency for Research on Cancer, World Health Organisation. LARC monographs on the evaluation of carcinogenic risks to humans. Vol 53, Occupational exposures in insecticide application, and some pesticides. Lyon: IARC, 1991

20 Eriksson M, Hardell L, Adami HO. Exposure to dioxins as a risk factor for soft tissue sarcoma: a population-based case-control study. $\mathcal{F}$ Natl Cancer Inst 1990;82:486-90.

21 Blair A, Hoar Zahm S. Cancer among farmers. Occupational medicine. State of the Ant Reviews 1991; 6:335-54.

22 International Agency for Research on Cancer, World Health Organisation, International Association of Cancer Registries. Cancer incidence in five continents. Vol 6. Lyon: IARC, 1992.

23 Stanfield AG, Diebold J, Noel H, et al. Update Kiel classification for lymphomas. Lancet 1988;i:292.

24 Dick FR, Maca RD. The lymph node in chronic lymphocytic leukemia. Cancer 1978;41:283-92.

25 Nanni O, Ricci M, Lugaresi C, Amadori D, Falcini F, Buiatti E. Iterative use of a priori exposure matrices to improve the characterization of chemical exposures in agricultural work studies. Scand $\mathcal{f}$ Work Environ Health 1993;19:191-9.

26 Fidanza F, Versiglioni N. Tabelle di composizione degli alimenti. In: Fidanza F, Liguori G, eds. Nutrizione umana. Napoli: Idelson, 1981;677-730.

27 Istituto Centrale di Statistica (ISTAT). Circoscrizioni statistiche. In: Metodi e norme, serie C. Roma: ISTAT, 1958.

28 Breslow NE, Day NE. Statistical methods in cancer research. Vol I. The analysis of case-control studies. Lyon: IARC 1980. (IARC Sci Publ No 32.)

29 SAS Institute SAS/STAT. Guide for personal computers version, 6th ed. Cary, NC:SAS Institute, 1987;1028.

30 SAS Institute SAS Technical report P-200, SAS/STAT soft ware: CALIS and LOGISTIC procedures, release 6.04. ware: CALIS and LOGISTIC proced

31 Cartwright RA, Bernard SM, Bird CC, Darwin CM O'Brien C, Richards IDG, et al. Chronic lymphocytic leukaemia: case control epidemiological study in Yorkshire. Leuk Res 1987;12:79-82.

32 Pearce NE, Sheppard RA, Howard JK, Fraser J, Lilley BM. Leukemia among New Zealand agricultural workers. A cancer registry-based study. Am $\mathcal{f}$ Epidemiol 1986;124:402-9.

33 Burmeister LF. Cancer mortality in Iowa farmers 1971-1978. F Natl Cancer Inst 1981;66:461-4.

34 Buesching DP, Wollstadt L. Cancer mortality among farmers [letter]. $\mathcal{F}$ Natl Cancer Inst 1984;72:503-4.

35 Pearce $N$, Bethwaite $P$. Increasing incidence of nonHodgkin's lymphoma: occupational and environmental factors. Cancer Res 1992;52:5496s-500s.

36 Johnson ES, Fischman HR, Matanoski GM, Diamond E. Occurrence of cancer in women in the meat industry. Brf Ind Med 1986;43:597-604.

37 Pearce N, Smith AH, Reif JS. Increased risks of soft tissue sarcoma, malignant lymphoma, and acute myeloid leukemia in abattoir workers. Am f Ind Med 1988;14: 63-72.

38 Hayes RB, Vineis P. Time dependency in human cancer. Tumori 1989;75:189-95. 